\title{
A Multicentre Study in UK Voice Clinics Evaluating the Non-invasive Reflux Diagnostic Peptest in LPR Patients
}

\author{
Peter W. Dettmar ${ }^{1}$ (1) $\cdot$ Mark Watson $^{2} \cdot$ Julian McGlashan $^{3}$ (D) Taran Tatla $^{4}$ (D) Andreas Nicholaides $^{5}$. \\ Kirsty Bottomley ${ }^{5} \cdot$ Nabil Jarad $^{6} \cdot$ Emma Stapleton $^{2} \cdot$ Rhianna K. Lenham $^{1} \cdot$ Jeanine Fisher ${ }^{1} \cdot$ Andrew D. Woodcock ${ }^{1}$
}

Accepted: 4 November 2019 / Published online: 6 December 2019

(C) The Author(s) 2019

\begin{abstract}
Questionnaires and invasive diagnostic tests are established for diagnosing gastro-esophageal reflux disease (GERD) but shown not to be sensitive or specific for diagnosing laryngopharyngeal reflux (LPR) where vast majority of reflux events are weakly acidic or non-acidic. The research question addressed in the current multicentre study was to determine if the measurement of salivary pepsin is a sensitive, specific and reliable diagnostic test for LPR. Five UK voice clinics recruited a total of 1011 patients presenting with symptoms of LPR and a small group of subjects $(n=22)$ recruited as asymptomatic control group. Twenty-six patients failed to provide demographic information; the total patient group was 985 providing 2927 salivary pepsin samples for analysis. Study participants provided 3 saliva samples, the first on rising with two samples provided post-prandial (60 min) or post-symptom (15 min). The control group provided one sample on rising and two post-prandial providing a total of 66 samples. Pepsin analysis was carried out using Peptest as previously described. High prevalence of pepsin in patient groups (75\%) represents a mean pepsin concentration of $131 \mathrm{ng} / \mathrm{ml}$. The greatest prevalence for pepsin was in the post-prandial sample (155 $\mathrm{ng} / \mathrm{ml})$ and the lowest in the morning sample $(103 \mathrm{ng} / \mathrm{ml})$. The mean pepsin concentration in the control group was $0 \mathrm{ng} / \mathrm{ml}$. Patients across all 5 clinics showed high prevalence of salivary pepsin (ranging from 69 to 86\%), and the overall sensitivity was $76.4 \%$ and specificity $100 \%$. Pepsin was shown to be an ideal biomarker for detecting airway reflux and LPR.
\end{abstract}

Keywords Reflux symptoms $\cdot$ Voice clinics $\cdot$ LPR $\cdot$ Saliva $\cdot$ Peptest $\cdot$ Pepsin

\section{Introduction}

Responsible for up to $10 \%$ of all otolaryngology consultations, laryngopharyngeal reflux (LPR) is a condition growing

This article is part of the Topical Collection on Medicine

Peter W. Dettmar

peter.dettmar@rdbiomed.com

1 RD Biomed Limited, Daisy Building, Castle Hill Hospital, Castle Road, Cottingham, East Yorkshire HU16 5JQ, UK

2 Doncaster Royal Infirmary, Armthorpe Road, Doncaster DN2 5LT, UK

3 Department of Otorhinolaryngology \& Head and Neck Surgery, Queen's Medical Centre Campus, University Hospital Nottingham, Nottingham NG7 2UH, UK

4 Northwick Park Hospital, Harrow, Middlesex HA1 3UJ, UK

5 York Hospital, Wigginton Road, York YO31 8HE, UK

6 Dolphin House, Bristol Royal Infirmary, Bristol BS2 8HW, UK in awareness [1]. Knowing that the retrograde movement of gastric contents including acid and pepsin into the esophagus can lead to gastro-esophageal reflux disease (GERD) [2,3], it is currently recognised that reflux reaches beyond the esophagus and into the larynx. This causes a myriad of persistent extra-esophageal symptoms (hoarseness, sore-throat, dysphagia and chronic cough) to be experienced and result in LPR [4-6]. There is also an ongoing debate as to whether LPR is associated with head and neck cancer $[7,8]$.

As heartburn is predominately absent in LPR, affecting less than $40 \%$ of all patients $[2,5]$, it is often referred to as silent reflux [7] and classified as an extra-esophageal disorder [3]. Due to LPR commonly being known as silent reflux, it is often misdiagnosed [2], costing the US economy greater than $\$ 52$ billion per year [5]. The original 'gold-standard' for LPR diagnosis was dual channel 24-h pH monitoring which lacks sensitivity and specificity due to its inability to detect nonacidic reflux events [9]. However, this has been somewhat superseded as the 'gold-standard' by MII-pH monitoring and there have been several studies published describing the use of MII-pH in monitoring and detection LPR [10-15]. 
After, initially being overlooked [16], salivary pepsin has been accepted as a diagnostic tool for LPR [17]. Only synthesised by the gastric chief cells [18], pepsin's presence in the larynx strongly implies a reflux event has taken place and pepsin is now regarded as the pathogenesis for LPR [17]. This recent awareness has led to the development of Peptest (RD Biomed Limited, UK), a novel, rapid, non-invasive diagnostic method for LPR - a lateral flow device which detects and measures pepsin concentration in expectorated saliva.

The aim of this study was to demonstrate how Peptest can be used to diagnose LPR in clinical settings, allowing Peptest availability to increase for clinic use in both primary and secondary care patients and those involved in clinical trials.

\section{Methods}

\section{Recruitment}

The patients $(n=1011)$ in the present study were recruited from 1 of 5 voice centres all of whom ran referral centres for patients suspected of having LPR. There were some differences between centres as to how patients were recruited but all had a structured history and clinical examination which included transnasal flexible laryngoscopy. One common factor between all patients in all 5 centres was that Peptest was used as the diagnostic test to support or aid exclusion of the diagnosis of LPR. All patients and control subjects provided three saliva samples for testing the presence of pepsin using Peptest (RD Biomed Limited, UK). Some of the patients had other diagnostic assessment including 24-h impedance and/or MII-pH impedance. Gaviscon or other antacids were stopped for $48 \mathrm{~h}$ prior to patients or controls providing saliva samples; however, patients could continue taking any PPI as this has no effect on pepsin detection.

\section{Doncaster Royal Infirmary}

Patients $(n=332)$ were recruited who had a clinical diagnosis of LPR. Peptest was used to improve diagnostic accuracy and prevent misdiagnosis. A small proportion of patients went on to have 24-h dual channel $\mathrm{pH}$ monitoring and high-resolution esophageal manometry.

\section{Northwick Park Hospital, North West London}

Patients ( $n=63$ ) were recruited by using Peptest as a screening tool after they had previously undergone numerous LPR diagnostic techniques providing contradictory results.

\section{Queen's Medical Centre, Nottingham}

Patients $(n=266)$ were recruited if they had one or more of the following LPR symptoms with little or no heartburn:

- Symptoms of chronic cough

- Sore throat

- Hoarseness or voice problems

- Lump sensation

- Excessive throat clearing of mucus or phlegm

Additional patients were recruited after nasoendoscopy supporting a diagnosis of throat irritation or inflammation being a contributory cause to their symptoms or signs such as chronic laryngitis, a granuloma, vocal cord cyst, polyp, nodules and muscle tension imbalance. Peptest was also used in patients who failed lifestyle/dietary change, who did not respond to anti-reflux medication and when there were multiple causes of their symptoms or signs.

\section{York Hospital}

Patients $(n=213)$ suspected of LPR underwent a standard 3part diagnostic assessment which included a structured history, a clinical examination which included transnasal flexible laryngoscopy and Peptest.

\section{Bristol Royal Infirmary}

Peptest was used and patients were recruited $(n=137)$ if they suffered with chronic cough paired with one of the following GERD symptoms:

- Significant peptic symptoms

- Overweight

- Voice changes

- Lump in the throat

- Food/postural related symptoms

- Absence of signs associated to structural lung disease, asthma or sinusitis

\section{Control Subjects}

Asymptomatic LPR age-matched control subjects $(n=22)$ were recruited from patients presenting at Doncaster Royal Infirmary who did not have a clinical diagnosis of LPR and had no symptoms of heartburn, regurgitation or any extra-esophageal symptoms for example chronic cough, hoarseness, sore throat and voice disorders. The mean age was 54.1 years (range 20 to 74) and a male/female ratio of 1:2.7 was present. This was compared with the clinically diagnosed LPR groups who had an average age of 59 years (range 17 to 99 ) and a male/female ratio of 1:1.9. 


\section{Sample Collection}

All samples were collected following a standard procedure in $30-\mathrm{ml}$ collection tubes which contained $0.5 \mathrm{ml}$ of $0.01 \mathrm{M}$ citric acid (Fig. 1). All participants provided three saliva samples, the first on rising prior to eating and cleaning their teeth. For patients, the other two samples were taken either post-prandial or post-symptom, and for the control group, the remaining two samples were both taken post-prandial. Post-prandial samples were collected $1 \mathrm{~h}$ after the participant consumed their main meal and any post-symptom samples were collected within 15 min of experiencing reflux symptoms. Patients/subjects were instructed to store all collected saliva samples at $4{ }^{\circ} \mathrm{C}$ prior to pepsin analysis. This was a fully validated procedure and samples were stored at $4{ }^{\circ} \mathrm{C}$ for a maximum of 3 days prior to pepsin analysis.

\section{Sample Analysis}

All collection tubes were centrifuged at $4000 \mathrm{rpm}$ for $5 \mathrm{~min}$ until a clear supernatant layer was visible. If not, the samples were centrifuged again and $80 \mu \mathrm{l}$ from the surface of the supernatant was drawn up into an automated pipette. The sample was transferred to a screw-top microtube containing $240 \mu \mathrm{l}$ of migration buffer $(\mathrm{pH} \mathrm{8.2)}$ and the solution was vortex mixed for $10 \mathrm{~s}$ (Fig. 1). A second pipette was used to transfer $80 \mu \mathrm{l}$ of the sample/migration buffer solution to the circular well of a lateral flow device (LFD) containing two unique human monoclonal antibodies; one to detect and the other to capture any pepsin present in the saliva sample (RD Biomed Limited, UK).
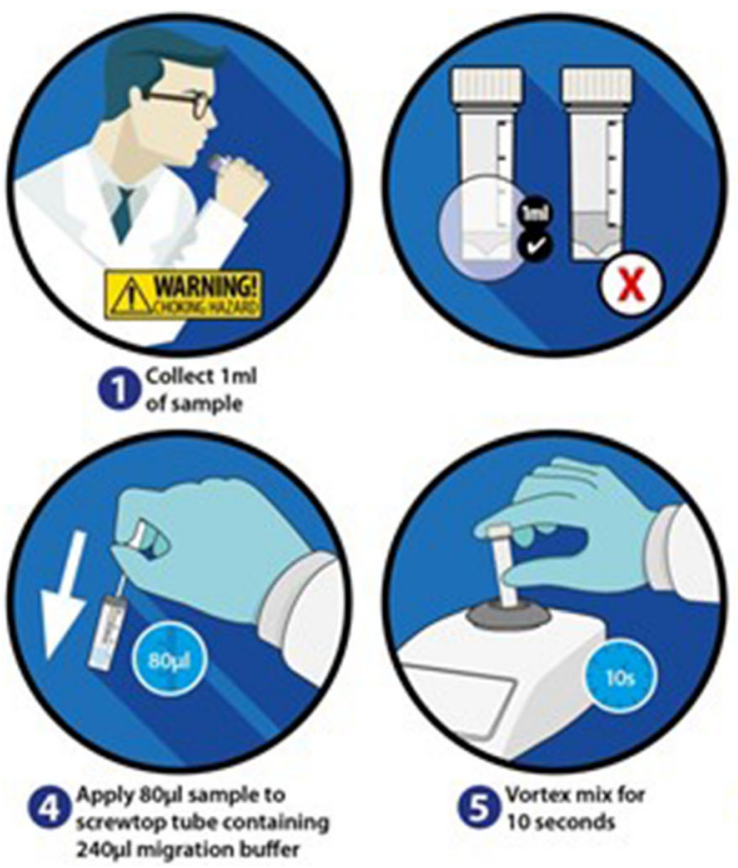

Fig. 1 Scheme of collection and analysis of saliva samples using Peptest
Fifteen minutes after introducing the clinical sample for pepsin analysis into the well of the Peptest, the LFD was placed into the Peptest reader to determine the intensity of the pepsin test line. Following intensive Peptest validation studies, the limit of detection of pepsin was determined to be $16 \mathrm{ng} / \mathrm{ml}$ and this lower limit of detection was used throughout the multicentre study. Pepsin concentrations $>16 \mathrm{ng} / \mathrm{ml}$ were considered positive.

Of the 2927 patient saliva samples collected and analysed for the presence of pepsin, approximately $10 \%$ of the samples were found to be viscous which meant that a useable supernatant was not present after first pass centrifugation. Viscous samples were vortex mixed for approximately $15 \mathrm{~s}$ and centrifuged at $4000 \mathrm{rpm}$ for $5 \mathrm{~min}$. If a supernatant layer was formed, the sample analysis was followed as above. If no supernatant layer was apparent following centrifugation, additional migration buffer $(500 \mu \mathrm{l})$ was added to the collection tube and the sample is vortex mixed for $15 \mathrm{~s}$ and centrifuged again at $4000 \mathrm{rpm}$ for $5 \mathrm{~min}$. If a supernatant layer was now formed, the sample was analysed as above and if no supernatant layer was visible, the centrifugation step was repeated.

\section{Statistical Analysis}

All patient and control subject data were anonymised prior to statistical analysis. Unpaired $t$ tests were performed between each voice centre using the statistical package GraphPad Prism 7 (GraphPad Software, San Diego, CA 92018, USA). $p$ values $<0.05$ were considered statistically significant.
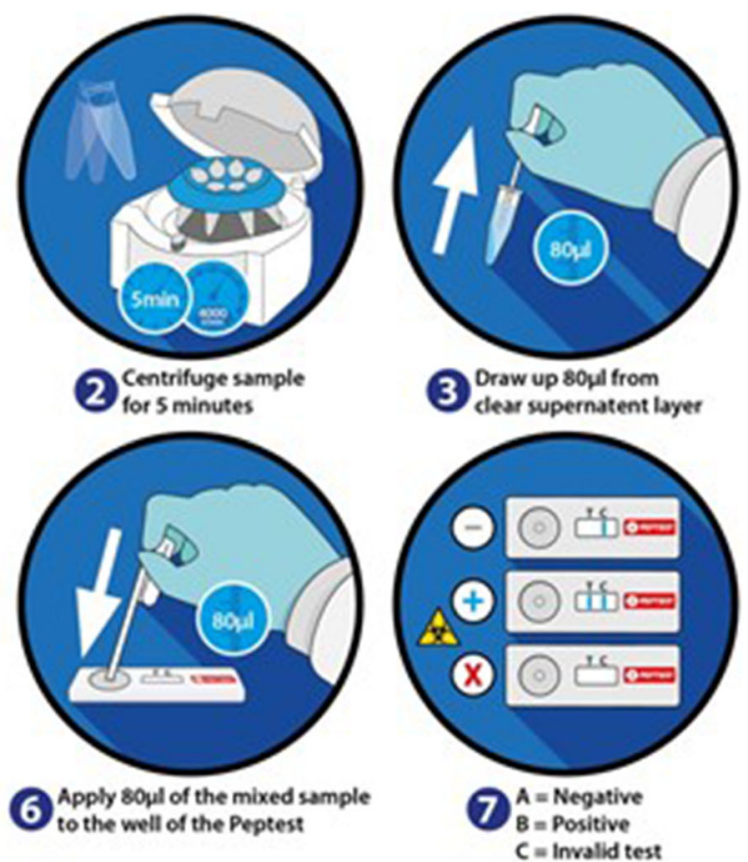
Table 1 Demographic characteristics provided by all patients

\begin{tabular}{|c|c|c|c|c|c|c|c|}
\hline & \multicolumn{2}{|c|}{ Gender } & \multicolumn{2}{|c|}{ Average age } & \multicolumn{2}{|c|}{ Age range } & \multirow{2}{*}{$\begin{array}{l}\text { Failure to } \\
\text { provide } \\
\text { information }\end{array}$} \\
\hline & Male & Female & Male & Female & Male & Female & \\
\hline All centres & 335 & 650 & 61 & 58 & $21-97$ & 17-99 & 26 \\
\hline Doncaster & 106 & 222 & 61 & 58 & $21-88$ & $17-90$ & 4 \\
\hline North West London & 33 & 30 & 60 & 57 & $37-86$ & $26-78$ & 0 \\
\hline Nottingham & 76 & 184 & 55 & 55 & $23-97$ & $20-92$ & 6 \\
\hline York & 87 & 117 & 63 & 65 & $27-89$ & $32-99$ & 9 \\
\hline Bristol & 33 & 97 & 66 & 58 & $32-99$ & $20-81$ & 7 \\
\hline
\end{tabular}

\section{Results}

A total of 1011 male and female patients recruited from five UK voice centres were used in this study. Table 1 refers to the total number of male and female participants from each centre. For Doncaster Royal Infirmary, the male/female ratio was 1:2.1 and 1:2.4 for Queen's Medical Centre, Nottingham. Northwick Park Hospital recruited 33 males and 30 females, with York hospital having a male/female split of 1:1.4. Finally, Bristol Royal Infirmary had 33 males and 97 females.

Breakdowns of age range for male and female patients from each of the five centres are presented in Table 1. The average age of the patient group (59 years, range 17-99) was similar to the control subjects (54.1 years, range $20-74)$. There was a total of 26 patients who provided only their gender, age or neither and were subsequently categorised as patients who failed to provide information. A breakdown of the number of patients who failed to provide information for each centre is shown in Table 1. Consequently, all statistical analysis was performed on the eligible 985 patients with complete demographic information.

The total number of saliva samples collected and analysed for the presence of pepsin using Peptest was 2927 for patients and 66 for control subjects. For the patient samples $(n=2927)$, the greatest prevalence of positive pepsin concentration was seen in the post-prandial samples $(154.8 \pm 4.985 \mathrm{ng} / \mathrm{ml}$ pepsin) and the lowest in the morning samples (102.9 \pm 5.187 $\mathrm{ng} / \mathrm{ml}$ pepsin (Fig. 2). Post-symptom samples had a positive pepsin concentration of $118.1 \pm 7.083 \mathrm{ng} / \mathrm{ml}$ ).

In the control group $0 / 22$ subjects had a positive saliva sample for the presence of pepsin; therefore, the mean pepsin concentration for the control subjects was $0 \mathrm{ng} / \mathrm{ml}$. It was unusual to observe zero pepsin in the control subjects; future studies should address this issue and a larger control group should be recruited. Several previous studies have reported that in healthy asymptomatic control subjects, one or more of the saliva samples analysed were positive for low levels of pepsin. For example, in the study reported by Hayat et al. [19] of the 87 asymptomatic controls, 33 had one or more saliva samples positive for pepsin (21\% of all control samples). In comparison with the control subjects, there was a high prevalence of saliva samples positive for pepsin in the patient population; 740 out of 985 patients were found to be pepsin positive in one or more sample (75.1\%). The mean pepsin concentration for all 2927 patient samples was 130.9 $\mathrm{ng} / \mathrm{ml}$.

Figure 3 illustrates the pepsin concentration for each saliva collection point at each of the 5 voice centres. The morning sample taken on waking was lower than the post-prandial and post-symptom saliva samples.

Unpaired $t$ tests were performed between each voice centre. It was observed that all five voice centres had a significantly higher mean pepsin concentration than in the control group, with all $p$ values $<0.0001$. Figure 4 displays York Hospital to have the highest mean pepsin concentration of $170.7 \mathrm{ng} / \mathrm{ml}$. The mean pepsin concentration range for all 5 voice centres was $97.7-170.7 \mathrm{ng} / \mathrm{ml}$. In Fig. 4, when summarising the total pepsin concentration for each study centre, the 3 saliva collection samples (on waking, post-prandial, post-symptom) were displayed as mean \pm SEM

In patients presenting with LPR symptoms, the prevalence of pepsin is consistent across the different voice centres.

\section{Time points}

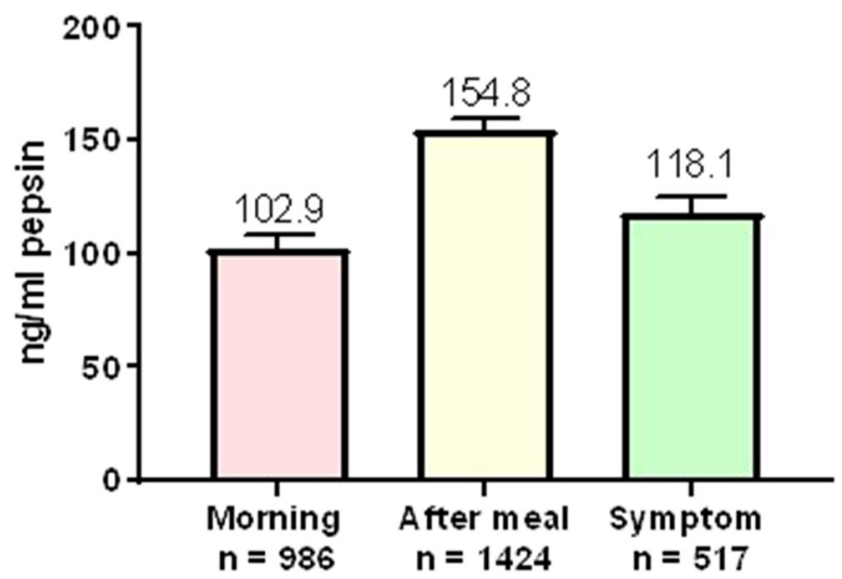

Fig. 2 Pepsin concentrations (ng/ml) recorded for all samples taken in each specific collection category 
Fig. 3 Mean pepsin concentration $(\mathrm{ng} / \mathrm{ml})$ for each saliva collection point at each study centre
Fig. 4 Mean pepsin

concentration $(\mathrm{ng} / \mathrm{ml})$ for each study centre with triple testing protocol showing each study centre to display high mean pepsin concentrations compared with the control group
Doncaster

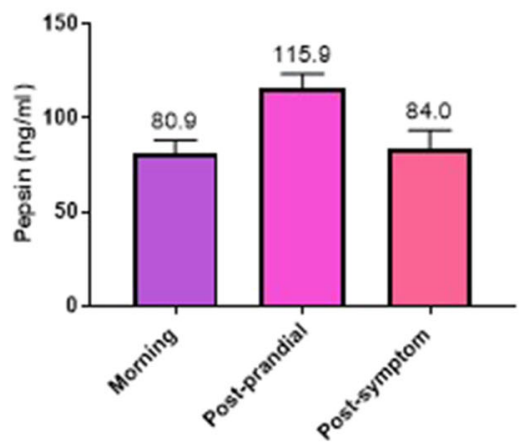

Nottingham

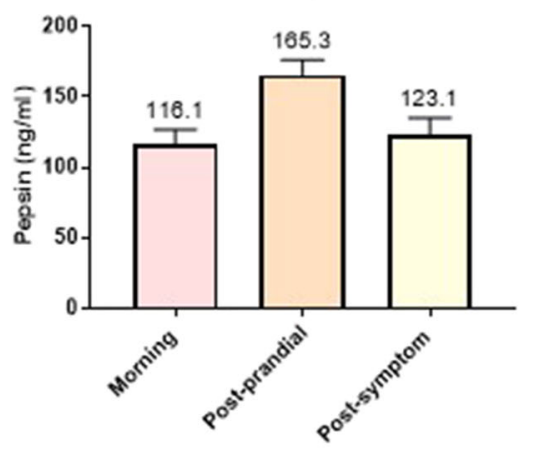

London

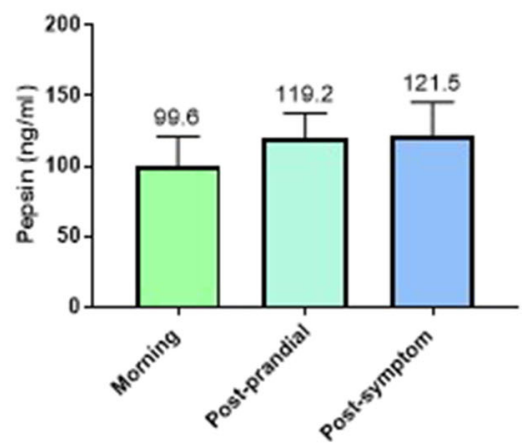

York

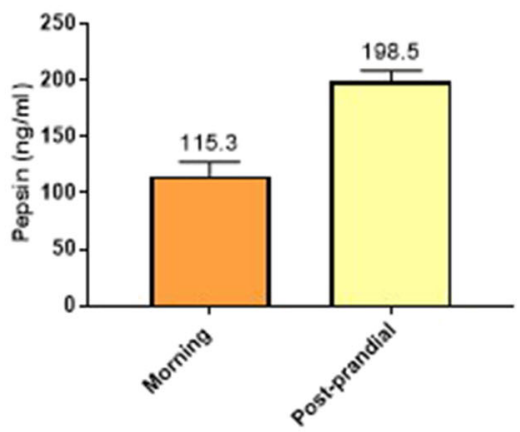

Bristol
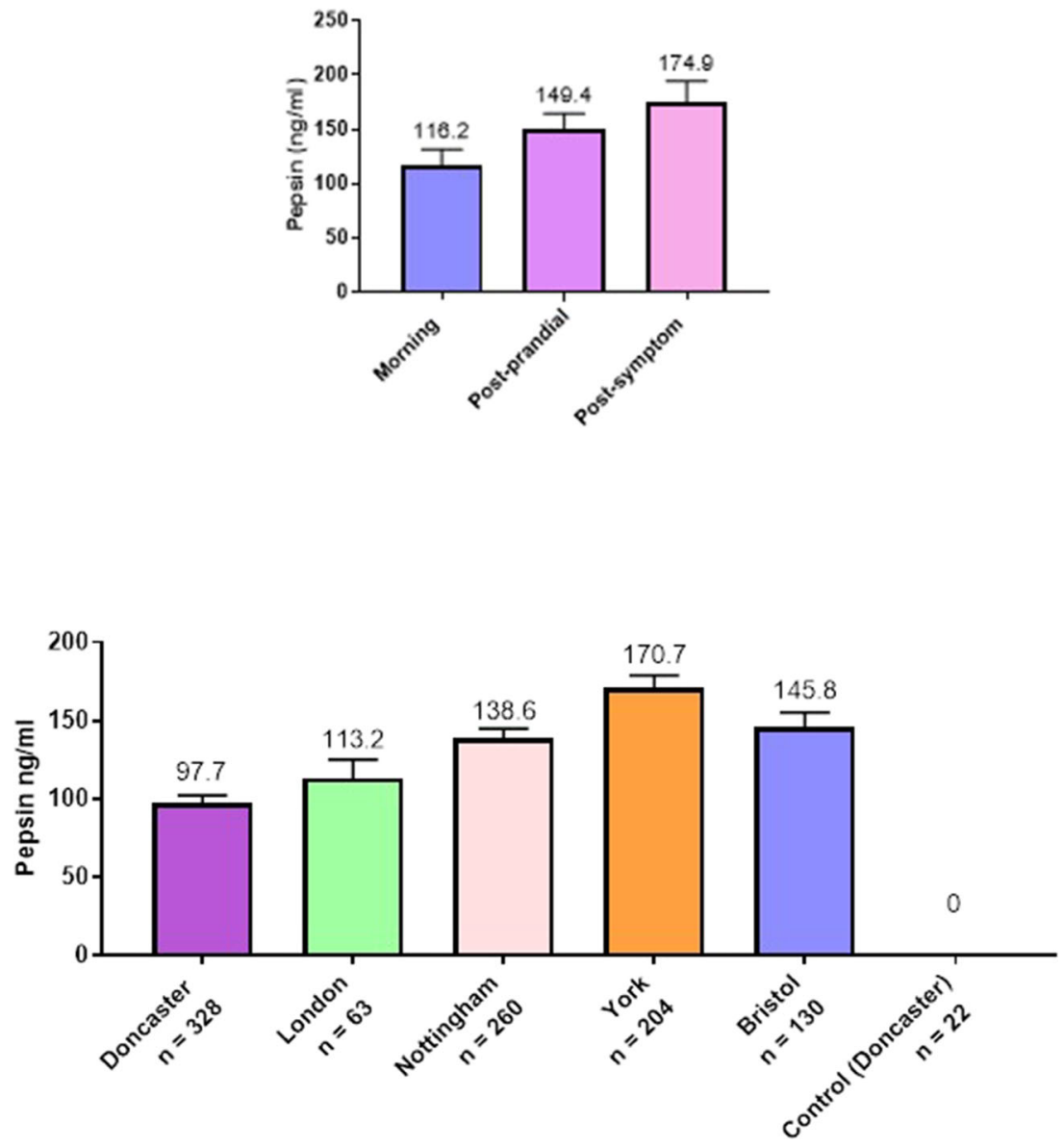
Table 2 Peptest results in LPR patients $(\boldsymbol{n}=985)$ with pepsin prevalence ranging from 69 to $86 \%$

\begin{tabular}{lllllll}
\hline $\begin{array}{l}\text { LPR study } \\
\text { location }\end{array}$ & $\begin{array}{l}\text { Doncaster } \\
\text { Royal } \\
\text { Infirmary, } \\
\text { Doncaster }\end{array}$ & $\begin{array}{l}\text { Northwick } \\
\text { Park, North } \\
\text { West } \\
\text { London }\end{array}$ & $\begin{array}{l}\text { Queen's } \\
\text { Medical } \\
\text { Centre, } \\
\text { Nottingham }\end{array}$ & $\begin{array}{l}\text { York } \\
\text { Hospital, }\end{array}$ & $\begin{array}{l}\text { Bork } \\
\text { Royal } \\
\text { Infirmary, } \\
\text { Bristol }\end{array}$ & $\begin{array}{l}\text { Doncaster } \\
\text { Royal } \\
\text { Infirmary, } \\
\text { Doncaster } \\
\text { (control) }\end{array}$ \\
\hline $\begin{array}{c}n= \\
\begin{array}{c}\text { Number of } \\
\text { positive } \\
\text { patients }\end{array}\end{array}$ & 328 & 63 & 260 & 204 & 130 & 22 \\
$\begin{array}{c}\text { Number of } \\
\text { negative } \\
\text { patients }\end{array}$ & 101 & 45 & 202 & 175 & 104 & 0 \\
$\begin{array}{c}\text { Percentage } \\
\text { positivity of } \\
\text { patients (\%) } \\
\text { (sensitivity) }\end{array}$ & 69.21 & 18 & 58 & 29 & 26 & 22 \\
\hline
\end{tabular}

Table 2 illustrates the range and prevalence of pepsin varying from 69.2 to $85.8 \%$ across each of the five centres. Table 2 also displays the strong association between pepsin and suspected LPR symptoms making pepsin a potential biomarker for detecting airway reflux and LPR.

In contrast to the LPR patients, the control subjects had three negative pepsin samples, generating a pepsin concentration of $0 \mathrm{ng} / \mathrm{ml}$. The breakdown for the total LPR patient population and the relatively small number of control subjects showed a sensitivity of $76.4 \%$, a specificity of $100 \%$, overall positive predictive value of 1 and a negative predictive value of 0.09 (Table 3).

\section{Discussion}

Pepsin is extremely effective at digesting proteins and is refluxed into areas of the upper digestive system where protection is poor, for example the esophagus [20] and also the airways and the lungs [21]. Pepsin also attaches to the epithelial surface and causes damage by proteolysis and over time increased reflux can cause considerable damage. Pepsin is also capable of interacting with cell surface receptors and to be taken up via receptor-mediated endocytosis and stored in intracellular vesicles that become increasingly acidic generating conditions that restore proteolytic activity [22, 23].

There have been a lot of publications describing studies of salivary pepsin in adults with GERD symptoms with many reporting good results comparable with those from using invasive diagnostics tests such as $\mathrm{pHmetry}$ or $\mathrm{pH}$-impedance

Table 3 Breakdown of patient sensitivity and specificity for males and females $(n=985)$ from each centre monitoring. The prevalence of LPR in the general population may be higher than previously thought and is postulated to be as high as 34\% [6]. However, this figure of $34 \%$ only refers to LPR sylmptoms assessed by the reflux symptom index (RSI) which can be argued is not specific enough and only accounts for some of the potential symptoms of LPR and other symptoms may follow which are not apparent at the time of patient self-assessment. This has significant implications at both primary and secondary care levels.

In a recently published meta-analysis [24] evaluating clinical outcomes of LPR treatment in 5781 suspected or confirmed LPR patients, a comparison with our current study is difficult as the primary objective of this latest meta-analysis was to investigate the therapeutic benefit of PPIs over placebo in patients suspected of having LPR. The meta-analysis major finding also suggested that diet and behavioural changes played a role in modulating the therapeutic effectiveness of PPIs.

Many studies in the past have supported the view that the diagnosis of LPR and symptoms of extra-esophageal reflux can be adequately diagnosed using the reflux symptom index (RSI) [25] and the reflux finding score (RFS) [26] questionnaires together with ambulatory $24-\mathrm{h}$ double probe $\mathrm{pH}$ monitoring or 24-h MII-pH monitoring. Missing from the battery of diagnostic tests is a validated LPR questionnaire correlating pepsin (Peptest) concentrations with LPR symptoms. This questionnaire needs to be prepared and validated in patient and control subjects. This area remains controversial and even using this battery of diagnostic tests is not considered to be accurate [27-29]. Recently, several studies have suggested that pepsin is a good biomarker for detecting LPR and that it can be considered as a reliable diagnostic marker [30-37]; this in turn has led to a valuable role for pepsin as a diagnostic test for both GERD and LPR [1,38-41] especially as Peptest is a rapid and non-invasive diagnostic test and patient compliance has been demonstrated to be high. This in turn suggests 
Peptest as an interesting alternative to the other more invasive diagnostic tests including the current gold standard. In particular, it would be an interesting alternative in patients who do not want to have MII-pH impedance or in those clinics that do not have access MII-pH impedance. Some studies have reported inconclusive results [42] and some studies have been more critical of pepsin analysis as still not being fully validated in terms of sensitivity and specificity [43]. This area remains somewhat controversial and what have been missing are large patient validation studies to fully identify whether salivary pepsin can reliably be used as an accurate diagnostic test. Two areas of controversy are as follows: (1) When is the best time to take the saliva samples? (2) What is the number of saliva samples required for an accurate diagnosis of LPR? This was questioned in a recent study published by Fortunato et al. (2017) [44]. In their study design, 8 saliva samples were collected, the first before the catheter was inserted into the patient, 6 samples prior to and after 3 meals, and the final sample immediately upon waking. For these samples, the volume of the saliva collected was measured using an adjustable 1-ml micropipette and then transferred to a 1-ml snap top tube for storage. In this study, $9.3 \%$ of the control subjects were Peptest positive versus $85.6 \%$ of the patients. What has also been missing is a large clinical study to address these critical questions and to determine the value of salivary pepsin in diagnosing LPR in a large multicentre study. There are still questions which need addressing, for example in patients who remain symptomatic, but in whom Peptest pepsin analysis is negative, we propose asking the patients to provide saliva samples on another day for repeat pepsin analysis. A future study will also evaluate how well treatment works in pepsin-positive patients presenting with cough and LPR symptoms to investigate if symptom improvement correlates with a drop in salivary pepsin concentration.

The results from some investigators have demonstrated that pepsin in saliva could be a marker for treatment success whereas oropharyngeal $\mathrm{pH}$ monitoring was shown not to be an adequate test [16]. This has largely been superseded by MII-pH impedance monitoring as the new gold standard for detection of LPR [45]. This diagnostic test [46, 47] is not available in many ENT clinics and is often reserved as a research tool only. However, the use and naming of MII-pH impedance as the gold standard in establishing LPR diagnostics is frequently questioned due to high false positive and false negative results. The interpretation is often difficult due to probe placement and anatomical differences. Future studies should address the direct comparison of MII-pH impedance diagnosis with Peptest pepsin analysis. We have attempted to address this issue and recently completed our own study validating Peptest in GERD and LPR patients undergoing impedance testing [48]. In this small study of only 20 reflux sufferers (10 GERD and 10 LPR), Peptest had a positive predictive value of $69 \%$ in detecting reflux compared with $88 \%$ for
MII-pH impedance. A similar positive predictive value was observed for Peptest against symptomatic episodes (69\%). Currently, there are well over 100 peer-reviewed publications describing the diagnostic potential of pepsin in LPR [7, 19, 49-58]. Many studies have incorporated the rapid simple pepsin spit saliva test into the battery of diagnostic procedures routinely used in ENT clinics such as questionnaires [36] like the RSI [25] and the RFS [26] together with a flexible transnasal laryngoscope. The most frequently used noninvasive pepsin diagnostic test is Peptest which was first introduced in the UK in 2010 [39] and is now registered as an in vitro diagnostic test in many countries. Other pepsin diagnostic tests which have largely been superseded by Peptest include enzyme linked immunosorbent assays (ELISA) [23] and Western blot techniques [23], enzymatic assays and immunohistochemistry [23, 52].

The mean ages of the patient groups (59 years) and the control group (54 years) were well matched. However, the limitation of the study was the size of the control group although smaller than the patient groups the saliva samples were pepsin negative. Future studies would benefit from a far larger control group similar to that used in Hayat et al. [19] and this remains a major criticism of the current study.

There were some differences between the salivary pepsin concentrations reported between the five centres although all the centres reported significantly higher pepsin levels in the LPR patients than in the control group ( $p<0.0001)$. The level of the consistency of the pepsin concentration across the patients evaluated in the five centres was generally good and fell within the range 97.7 to $170.7 \mathrm{ng} / \mathrm{ml}$. In terms of significance between centres, the LPR patients in York reported the higher salivary pepsin concentrations compared with the other four centres $(p<0.0001$ to $p<0.0462)$. The Doncaster Royal Infirmary reported a similar mean pepsin concentration to that of Northwick Park Hospital in North West London and both centres were generally significantly lower than the other three centres $(p<0.0001$ to $p<0.0392)$. This can be explained as both centres were not recruiting first line LPR patients but patients who were attending the clinics for examination after receiving unclear and contradictory diagnostic results and fewer patients were identified as primarily LPR patients until tested with Peptest. One very valid criticism of the current study is the small control group recruited and the fact that the asymptomatic subjects were found to have zero pepsin present which based on previous control populations was a surprising observation. Future studies in this area would also benefit from breaking down the patient groups even further and conducting subgroup analysis, for example on patients presenting primarily with chronic cough or who present with the symptoms of hoarseness or voice disorders. Finally, the current multicentre study was aimed at addressing the use of pepsin analysis as a marker of LPR in secondary care and further studies would be beneficial in investigating the use 
of this simple rapid diagnostic test in the primary care environment.

The method of saliva sample collection has been well validated [33]. The total number of saliva samples analysed for pepsin in the current multicentre study was 2927 and the best time for collecting saliva samples for salivary pepsin analysis has been answered in the current study with the post-prandial saliva collection time showing the greatest pepsin prevalence. Clearly, although the timing of the sample collection has shown to be important, future studies also need to look closer on the influence of diet as well as sample timing.

The current multicentre study carried out in over one thousand patients with suspected LPR demonstrated Peptest to be a simple non-invasive test capable of diagnosing LPR with an overall sensitivity of $76.4 \%$ and specificity of $100 \%$ and goes some way in addressing the frequently asked questions in this important clinical area. However, an important question not addressed by this current multicentre study is how treatment options across the different centres influence the outcome of the LPR symptoms seen within patient groups. This area remains controversial and requires further investigation.

\section{Compliance with Ethical Standards}

Conflicts of Interest Peter W. Dettmar is a director of RD Biomed Limited and Rhianna K. Lenham. Jeanine Fisher and Andrew D. Woodcock are employed by RD Biomed Limited. Mark Watson, Julian McGlashan, Taran Tatla, Andreas Nicholaides, Kirsty Bottomley, Nabil Jarad and Emma Stapleton declare that they have no conflict of interest.

Research Involving Human Participants The patients and control subjects used in the present study were recruited following referral to an ENT clinic for routine diagnostic assessment for LPR. All patient and control subject data was anonymised prior to statistical analysis.

Informed Consent The rights of participants whose data was used in the present study was not infringed. All the participants in the study were attending a clinic for routine diagnostic assessment for LPR. All data collected from all centres was anonymised and no personal data was ever discussed or used in the data analysis. Complete anonymity was achieved and maintained and no personal data identifying an individual was ever disclosed.

Ethical Approval All procedures performed in studies involving human participants were in accordance with the ethical standards of the institutional and/or national research committee and with the 1964 Helsinki Declaration and its later amendments or comparable ethical standards.

Open Access This article is licensed under a Creative Commons Attribution 4.0 International License, which permits use, sharing, adaptation, distribution and reproduction in any medium or format, as long as you give appropriate credit to the original author(s) and the source, provide a link to the Creative Commons licence, and indicate if changes were made. The images or other third party material in this article are included in the article's Creative Commons licence, unless indicated otherwise in a credit line to the material. If material is not included in the article's Creative Commons licence and your intended use is not permitted by statutory regulation or exceeds the permitted use, you will need to obtain permission directly from the copyright holder. To view a copy of this licence, visit http://creativecommons.org/licenses/by/4.0/.

\section{References}

1. Calvo-Henríquez C, Ruano-Ravina A, Vaamonde P, MartínezCapoccioni G, Martín-Martín C. Is pepsin a reliable marker of laryngopharyngeal reflux? A systematic review. Otolaryngol Head Neck Surg. 2017;157(3):385-91.

2. Ocak E, Kubat G, Yorulmaz I. Immunoserologic. Pepsin detection in the saliva as a non-invasive rapid diagnostic test for laryngopharyngeal reflux. Balkan Med J. 2015;32:46-50.

3. Gelardi M, et al. Clinical-diagnostic correlations in laryngopharyngeal reflux (LPR). The role of peptest. Int J Open Access Otolaryngol. 2017;1(1):1-8.

4. Ozmen S, Yücel OT, Sinici I, Ozmen OA, Süslü AE, Oğretmenoğlu $\mathrm{O}$, et al. Nasal pepsin assay and $\mathrm{pH}$ monitoring in chronic rhinosinusitis. Laryngoscope. 2008;118(5):890-4.

5. Luebke KE, Samuels TL, Johnston N. The role of pepsin in LPR: will it change our diagnostic and therapeutic approach to the disease? Curr Otorhinolaryngol Rep. 2016;4(1):55-62.

6. Kamani T, Penney S, Mitra I, Pothula V. The prevalence of laryngopharyngeal reflux in the English population. Eur Arch Otorhinolaryngol. 2012;269(10):2219-25.

7. Salihefendic N, Zildzic M, Čabrić E. Laryngopharyngeal reflux disease - LPRD. Mediev Archaeol. 2017;71(3):215-8.

8. Riley CA, Wu EL, Hsieh MC, Marino MJ, Wu XC, McCoul E. Association of gastroesophageal reflux with malignancy of the upper aerodigestive tract in elderly patients. JAMA Otolaryngol Head Neck Surg. 2018;144(2):140-8.

9. Rasijeff AMP, et al. Does salivary pepsin measurement change diagnostic outcome in patients investigated by $24 \mathrm{~h}$ ph monitoring? Gut. 2015;64(Suppl 1):A287.3-A288.

10. Ford CN. Evaluation and management of laryngopharyngeal reflux. Jama. 2005;294(12):1534-40.

11. Tutuian R, Mainie I, Agrawal A, Adams D, Castell DO. Nonacid reflux in patients with chronic cough on acid-suppressive therapy. Chest. 2006;130(2):386-91.

12. Oelschlager BK, Quiroga E, Isch JA, Cuenca-Abente F. Gastroesophageal and pharyngeal reflux detection using impedance and 24-hour $\mathrm{pH}$ monitoring in asymptomatic subjects: defining the normal environment. J Gastrointest Surg. 2006;10(1):54 62.

13. Vela MF. Multichannel intraluminal impedance and $\mathrm{pH}$ monitoring in gastroesophageal reflux disease. Expert Rev Gastroenterol Hepatol. 2008;2(5):665-72.

14. Formanek M, et al. Comparison of impedance and pepsin detection in the laryngeal mucosa to determine impedance values that indicate pathological laryngopharyngeal reflux. Clin Trans1 Gastroenterol. 2017;8(10):e123.

15. Sakin YS, Vardar R, Sezgin B, Cetin ZE, Alev Y, Yildirim E, et al. The diagnostic value of 24-hour ambulatory intraesophageal $\mathrm{pH}$ impedance in patients with laryngopharyngeal reflux symptoms comparable with typical symptoms. United European Gastroenterol J. 2017;5(5):632-40.

16. Weitzendorfer M, Pfandner R, Antoniou SA, Langsteger W, Witzel $\mathrm{K}$, Emmanuel $\mathrm{K}$, et al. Role of pepsin and oropharyngeal $\mathrm{pH}$ monitoring to assess the postoperative outcome of patients with laryngopharyngeal reflux: results of a pilot trial. J Laparoendosc Adv Surg Tech. 2017;27(9):937-43.

17. Adkins $\mathrm{C}$, et al. Salivary pepsin concentrations are higher for patients with reflux associated laryngeal symptoms: a prospective pilot study. Gastroenterology. 2015;148(4):S-610.

18. Barona-Lleó L, Duval C, Barona-de Guzmán R. Salivary pepsin test: useful and simple tool for the laryngopharyngeal reflux diagnosis. Acta Otorrinolaringol (English Edition). 2018;69(2):80-5. 
19. Hayat JO, Gabieta-Somnez S, Yazaki E, Kang JY, Woodcock A, Dettmar P, et al. Pepsin in saliva for the diagnosis of gastrooesophageal reflux disease. Gut. 2015;64(3):373-80.

20. Roberts NB. Review article: human pepsins - their multiplicity, function and role in reflux disease. Aliment Pharmacol Ther. 2006;24:2-9.

21. Johnston N. Review article: uptake of pepsin at pH 7 - in non-acid reflux- causes inflammatory, and perhaps even neoplastic, changes in the laryngopharynx. Aliment Pharmacol Ther. 2011;33(Suppl 1):13-20.

22. Johnston N, et al. Receptor-mediated uptake of pepsin by laryngeal epithelial cells. Ann Otol Rhinol Laryngol. 2008;116:934-8.

23. Samuels T, et al. Local synthesis of pepsin in barrett's esophagus and the role of pepsin in esophageal adenocarcinoma. Ann Otol Rhinol Laryngol. 2015;124(11):1-10.

24. Lechien JR, Saussez S, Schindler A, Karkos PD, Hamdan AL, Harmegnies B, et al. Clinical outcomes of laryngopharyngeal reflux treatment: A systematic review and meta-analysis. Laryngoscope. 2019;129(5):1174-87.

25. Belafsky PC, Postma GN, Koufman JA. Validity and reliability of the reflux symptom index (RSI). J Voice. 2002;16:274-7.

26. Belafsky PC, Postma GN, Koufman JA. The validity and reliability of the reflux finding score (RFS). Laryngoscope. 2001;111:1313-7.

27. Duricek M, et al. Acidic pharyngeal reflux does not correlate with symptoms and laryngeal injury attributed to laryngopharyngeal reflux. Dig Dis Sci. 2018.

28. Lechien JR, Schindler A, de Marrez LG, Hamdan AL, Karkos PD, Harmegnies B, et al. Instruments evaluating the clinical findings of laryngopharyngeal reflux: a systematic review. Laryngoscope. 2019;129(3):720-36.

29. Lechien J, Saussez S, Karkos PD. Laryngopharyngeal reflux disease: clinical presentation, diagnosis and therapeutic challenges in 2018. Curr Opin Otolaryngol Head Neck Surg. 2018:26.

30. Johnston N, et al. Laryngopharyngeal reflux and GERD. Ann N Y Acad Sci. 2013;1300(1):71-9.

31. Hayat JO, Yazaki E, Moore AT, Hicklin L, Dettmar P, Kang JY, et al. Objective detection of esophagopharyngeal reflux in patients with hoarseness and endoscopic signs of laryngeal inflammation. J Clin Gastroenterol. 2014;48(4):318-27.

32. Li Y-W, Sifrim D, Xie C, Chen M, Xiao YL. Relationship between salivary pepsin concentration and esophageal mucosal integrity in patients with gastroesophageal reflux disease. J Neurogastroenterol Motil. 2017;23(4):517-25.

33. Yong Ryu I, et al. Comparison of methods for collecting saliva for pepsin detection in patients with laryngopharyngeal reflux. Korean J Otorhinolaryngol Head Neck Surg. 2017;60:570-4.

34. Ren J, Zhao Y, Wang J, Ren X, Xu Y, Tang W, et al. PepsinA as a marker of laryngopharyngeal reflux detected in chronic rhinosinusitis patients. Otolaryngol Head Neck Surg. 2017;156(5):893-900.

35. Guo Z, Wu H, Jiang J, Zhang C. Pepsin in saliva as a diagnostic marker for gastroesophageal reflux disease: a meta-analysis. Med Sci Monit. 2018;24:9509-16.

36. Salvatore EA, Giada M, Ciprandi G. The clinical relevance of gastroesophageal reflux disease and laryngopharyngeal reflux in clinical practice, in esophageal cancer and beyond, J.Chai, Editor. 2018, IntechOpen. p. 47-65.

37. Samuels T, Johnston N. Pepsin as a marker of extraesophageal reflux. Ann Otol Rhinol Laryngol. 2010;119:203-8.

38. Johnston N, et al. Rationale for targeting pepsin in the treatment of reflux disease. Ann Otol Rhinol Laryngol. 2010;119:547-58.

39. Bardhan KD, Strugala V, Dettmar PW. Reflux revisited: advancing the role of pepsin. Int J Otolaryngol. 2012;2012:1-13.

40. Stapleton E, Watson M, Strugala V, Dettmar P. Salivary pepsin assay as a diagnostic test for laryngopharyngeal reflux, in 15th British Academy Conference in Otolaryngology and ENT Expo. 2015.
41. Strugala V, Bardhan KD, McGlashan J, Dettmar PW. Differentiation between LPR and GORD with the use of a simple non-invasive diagnostic test for reflux by detection of pepsin in expectorated saliva, in 15th British Academic Conference in Otolaryngology and ENT Expo. 2015.

42. Wang J, Zhao Y, Ren J, Xu Y. Pepsin in saliva as a diagnostic biomarker in laryngopharyngeal reflux: a meta-analysis. Eur Arch Otorhinolaryngol. 2018;275(3):671-8.

43. Vaezi MF, Sifrim D. Assessing old and new diagnostic tests for gastroesophageal reflux disease. Gastroenterology. 2018;154(2):289-301.

44. Fortunato JE, D'Agostino RB Jr, Lively MO. Pepsin in saliva as a biomarker for oropharyngeal reflux compared with 24-hour esophageal impedance/pH monitoring in pediatric patients. Neurogastroenterol Motil. 2017;29(2).

45. Cumpston EC, Blumin JH, Bock JM. Dual pH with multichannel intraluminal impedance testing in the evaluation of subjective laryngopharyngeal reflux symptoms. Otolaryngol Head Neck Surg. 2016;155(6):1014-20.

46. Karamanolis G, Kotsalidis G, Triantafyllou K, Polymeros D, Gaglia A, Fessatou S, et al. Yield of combined impedance-pH monitoring for refractory reflux symptoms in clinical practice. J Neurogastroenterol Motil. 2011;17(2):158-63.

47. Khan MQ, Alaraj A, Alsohaibani F, al-Kahtani K, Jbarah S, alAshgar H. Diagnostic utility of impedance-pH monitoring in refractory non-erosive reflux disease. J Neurogastroenterol Motil. 2014;20(4):497-505.

48. Bor, S., Capanoglu, D., Vardar, R., Woodcock, A.D., Fisher, J and Dettmar, P.W.,, Validation of Peptest ${ }^{\mathrm{TM}}$ in Gastro-esophageal reflux disease and Laryngopharyngeal reflux patients undergoing impedance testing. J Gastrointest Liver Dis. In Press., (2019).

49. Wassenaar E, Johnston N, Merati A, Montenovo M, Petersen R, Tatum $\mathrm{R}$, et al. Pepsin detection in patients with laryngopharyngeal reflux before and after fundoplication. Surg Endosc. 2011;25(12):3870-6.

50. Bor S, Capangolu DS, Yildirim E, Vardar R, Woodcock A, Dettmar PW. The validation of peptest a new non-invasive technology for the diagnosis of laryngopharangeal reflux (LPR). Gut. 2012;61(Suppl 3):A83.

51. Hayat JO, et al. Novel techniques for assessing oesophagopharyngeal reflux in patients with hoarseness and suspected laryngopharyngeal reflux. Gut. 2012;61(Suppl 2):A260.2-A261.

52. Sereg-Bahar M, et al. Pepsin and bile acids in saliva in patients with laryngopharyngeal reflux - a prospective comparative study. Clin Otolaryngol. 2014;40(3):234-9.

53. Spyridoulias A, Lillie S, Vyas A, Fowler SJ. Detecting laryngopharyngeal reflux in patients with upper airways symptoms: symptoms, signs or salivary pepsin? Respir Med. 2015;109(8):963-9.

54. Falk G, Vivian S. Laryngopharyngeal reflux: diagnosis, treatment and latest research. Eur Surg. 2016;48(2):74-91.

55. Du X, et al. The diagnostic value of pepsin detection in saliva for gastro-esophageal reflux disease: a preliminary study from China. BMC Gastroenterol. 2017;17(107):1-9.

56. Wang C-P, Wang CC, Lien HC, Lin WJ, Wu SH, Liang KL, et al. Saliva pepsin detection and proton pump inhibitor response in suspected laryngopharyngeal reflux: pepsin detection in laryngopharyngeal reflux. Laryngoscope. 2019;129:709-14.

57. Barona-Lleo L, Barona-De Guzman R, Krstulovic C. The diagnostic usefullness of the salivary pepsin test in symptomatic laryngopharyngeal reflux. J Voice. 2018; In Press.

58. Johnston N, Dettmar PW, Ondrey FG, Nanchal R, Lee SH, Bock JM. Pepsin: biomarker, mediator, and therapeutic target for reflux and aspiration. Ann N Y Acad Sci. 2018;1434(1):282-9.

Publisher's Note Springer Nature remains neutral with regard to jurisdictional claims in published maps and institutional affiliations. 